\title{
The Search for Excellence in Technology Education
}

\author{
Karen F. Zuga \\ David C. Bjorkquist ${ }^{1}$
}

There is an intense desire to create excellence in technology education, or, if preferred, industrial arts. This is not something that has been brought on by recent efforts to renew the field although the zeal of the quest has been heightened in recent years. In the process of trying to encourage advancements in programs, one of the thrusts has been to identify exemplary practices and hold them up as examples. In some cases these practices have been by real teachers and schools, while in others they have been projected and described by visionaries. In large part, the models are of the content to be taught and are set in opposition to existing subject matter organization. Less attention is given to methods of instruction.

The new favorites are those subjects that are representative of so called "high technology." These subjects are appealing to many who are fixated by the mechanization of modern life and they give the outward appearance of being advanced subject matter within the schools. Status symbols of success in the field are the artifacts of advanced technology in the laboratories where teaching occurs. Wide-belt sanders have been replaced by computers with more megabytes as rewards for doing what is right as a teacher. It is a rare person who has escaped this influence. Teachers, teacher educators, textbook publishers, equipment vendors, researchers, school administrators, school boards, and others associated with or supporting technology education have been lured by the appeal of newer, faster, higher capacity (but smaller) hardware. In many instances, there is software to go with it. It is argued that this is representative of the day. "Look at industry!" or "Look at technology!" is the petition of those who would teach technology education - a subject field conceived as general education and dedicated to liberating the minds of its learners. There is confusion about the interpretation of the purposes that we purport to fulfill and how to achieve them.

With the focus on the content of technology education, insufficient attention is given to the methodology of instruction. While learning objectives such as problem solving, innovation, and higher order thinking skills are considered to be important, too few learning experiences are designed to accomplish them. When the primary activities of learning are intended to place students in contact with the newest technological mechanisms available rather than to engage their minds in the identification and solution of problems, opportunities are missed. The seductiveness of the machines lures students and teachers away from the things that could serve them best. There will be newer and smarter machines tomorrow, making the knowledge acquired about today's model very perishable. By contrast, the learned ability to develop ideas and create solutions will always serve the learner.

It is apparent that the newest technology available does not lead to the best instruction in technology education and it does not result in the achievement of the primary purpose of the field. In many instances, flashy equipment has been used to camouflage inferior teaching. Students learn to manipulate robots in exercises that are tightly described by the teacher within timelines controlled by the school schedule, or to find answers to problems that no one really cares about. At the same time, some teachers of woodworking, metalworking, crafts, or drafting are teaching students how to solve problems that they have identified, how to develop methods for study, and how to evaluate alternative outcomes in systematic fashion. These teachers are developing technologically literate people. Judgements about good and poor teaching in technology education are being made on the basis of the wrong criteria. Teaching woodworking is not all bad and teaching computers is not all good. There are opportunities in both subjects to prepare students for the future as well as to deny them learning experiences that will engage their powers to do such things as identify and solve problems.

Observations at a local school district over the past five years illustrate how traditional course work can provide problem-solving experiences and contemporary course work can negate critical thinking and problem solving.

1 Karen Zuga is Assistant Professor, Industrial Technology Education, The Ohio State University. David Bjorkquist is Professor, Division of Industrial Education, University of Minnesota. 
Teachers of technology education have a major role in organizing curriculum and instruction. For example, two teachers - one teaching a traditional subject and one teaching a contemporary subject - could employ two different approaches to curriculum and instruction, thereby creating a traditional environment within a communication course and an innovative environment within a woodworking course. The communication teacher may be teaching students about computers, lasers, and robots, but doing this with specific activities such as digitizing a picture, programming a robot to talk, and transmitting sound via a laser beam. This teacher's course could require all students to perform the same activities such as reading the same selections of text, answering the same study questions, and performing the same activities. The students should then take the same test and move on to more of the exact duplicate activities as all the other students in the class. Students would plod through this "innovative" course much in the same way that students in previous years all learned the parts of the hand plane, how to square a board with hand tools and build a bookshelf using teacher-made templates. On the other hand, the woodworking teacher's students could be learning traditional content, but having a very different kind of experience. Within the context of woodworking, the students may be exposed to basic demonstrations of tools and equipment, but must design and create their own project, conduct a study on the use of wood in contemporary cabinet making or construction, and study the effects of deforestation upon the earth. This kind of "traditional" course provides many opportunities for students to be creative, improve their problem solving abilities, become critical consumers, and develop technological literacy.

Too often, a blanket critique of anything labeled with a traditional content descriptor is made. Given the choice of taking one of the two courses mentioned above, students probably have a better chance of becoming critical thinkers and problem solvers in the woodworking course. The way in which the course is organized and conducted demonstrates a type of educational activity that attempts to prepare students to be independent thinkers and problem solvers. The specific content of the course becomes a secondary issue; the activities provided for the students become the primary issue. This approach to teaching should not be criticized or abandoned in favor of instruction that is a system for putting students through inconsequential exercises with the latest mechanisms available to a particular school. If technology educators truly wish to achieve excellence, then the valuable traditional practices of teaching must be preserved and incorporated into the practice of technology education. 